\title{
Estimating travel reduction associated with the use of telemedicine by patients and healthcare professionals: proposal for quantitative synthesis in a systematic review
}

Richard Wootton ${ }^{1 *}$, Kambiz Bahaadinbeigy ${ }^{2,4}$ and David Hailey ${ }^{3}$

\begin{abstract}
Background: A major benefit offered by telemedicine is the avoidance of travel, by patients, their carers and health care professionals. Unfortunately, there is very little published information about the extent of avoided travel. We propose to undertake a systematic review of literature which reports credible data on the reductions in travel associated with the use of telemedicine.

Method: The conventional approach to quantitative synthesis of the results from multiple studies is to conduct a meta analysis. However, too much heterogeneity exists between available studies to allow a meaningful meta analysis of the avoided travel when telemedicine is used across all possible settings. We propose instead to consider all credible evidence on avoided travel through telemedicine by fitting a linear model which takes into account the relevant factors in the circumstances of the studies performed. We propose the use of stepwise multiple regression to identify which factors are significant.

Discussion: Our proposed approach is illustrated by the example of teledermatology. In a preliminary review of the literature we found 20 studies in which the percentage of avoided travel through telemedicine could be inferred (a total of 5199 patients). The mean percentage avoided travel reported in the 12 store-and-forward studies was $43 \%$. In the 7 real-time studies and in a single study with a hybrid technique, $70 \%$ of the patients avoided travel. A simplified model based on the modality of telemedicine employed (i.e. real-time or store and forward) explained $29 \%$ of the variance. The use of store and forward teledermatology alone was associated with $43 \%$ of avoided travel. The increase in the proportion of patients who avoided travel (25\%) when real-time telemedicine was employed was significant $(P=0.014)$. Service planners can use this information to weigh up the costs and benefits of the two approaches.
\end{abstract}

\section{Background}

Telemedicine can be defined as the use of information and communications technology to provide health care services for persons who are some distance from the provider. Thus it is a technique, or process for service delivery, which makes use of various technologies to exchange information. A major benefit offered by telemedicine is the avoidance of travel, by patients, their carers and health care professionals. Use of telemedicine

\footnotetext{
* Correspondence: r_wootton@pobox.com

'Norwegian Centre for Integrated Care and Telemedicine, University Hospital of North Norway, PO Box 6060, N-9038 Tromsø, Norway

Full list of author information is available at the end of the article
}

can reduce the cost and time of any travel required, and lead to faster delivery of medical services. Avoided travel is also an environmental benefit of telemedicine, and one that is becoming increasingly important [1].

In designing a new telemedicine service, the planner needs to know what avoided travel to expect. Clearly this will depend on the types of patients and the specialties involved. It is also likely to depend on the type of telemedicine employed (i.e. real time or store and forward) and a number of other factors. Unfortunately, only limited information exists about the extent of savings that can be expected for different telemedicine applications, and there is very little published information about avoided

\section{C) Biomed Central}


travel. Relatively few publications have provided details of travel savings through routine use of established telemedicine applications in health care systems.

We therefore propose to undertake a systematic review of literature which reports credible data on the reductions in travel associated with the use of telemedicine. The intention is to summarise the information about the proportion of avoidable travel possible through use of different telemedicine applications in different contexts. For the purposes of our study avoidable travel is defined as the proportion of consultations or other episodes of care using telemedicine in which patients, carers or health professionals do not have to travel to another centre.

\section{Methods/Design Review}

The review will identify studies in which the percentage of avoided travel or avoided referrals through use of telemedicine was measured or inferred. This information will then be used to make the best estimate possible of the true value of the percentage travel avoided through use of telemedicine in different medical specialties. Because telemedicine is often employed in very different ways within a given speciality, it is necessary to take account of the relevant factors. For example, telemedicine has been used in cardiology for many years. However, there are obvious differences between say the use of telecardiology to support general practitioners and the use of telecardiology in paediatric work. In the former, there may be store-and-forward transmission of an ECG recorded in an adult patient suspected of having a myocardial infarction; in the latter, there may be real-time transmission of an echocardiograph from a new born baby suspected of a cardiac defect.

Thus for each "set of circumstances" (i.e. for each telemedicine application in a given specialty), the values that are reported in the reviewed papers, or that can be derived from the data that they include, can be considered as an underlying true value plus an error component:

$$
\mathrm{Y}_{\mathrm{i}}=\beta_{0}+\beta_{1} \cdot \mathrm{X}_{\mathrm{i}}+\varepsilon_{\mathrm{i}}
$$

where $Y_{i}$ is the predicted value for avoided travel in a given set of circumstances, $\mathrm{i}$;

$\beta_{0}$ is the baseline value (intercept);

$\beta_{\mathrm{i}}$ is the coefficient relevant to the circumstances, $X_{\mathrm{i}}$; $\varepsilon_{\mathrm{i}}$ is the error term.

The error term may have both systematic and random components. The question of defining the systematic element is complex and not readily addressed [2]. We propose to define the inclusion/exclusion criteria for reported studies so that the mean systematic errors associated with avoided travel can be ignored for the purposes of our review.

Our original aim was to find studies where the effect of using telemedicine on patient travel was explicitly addressed, e.g. comparative studies in which patient travel was reported for a telemedicine arm and for a control arm. However, a preliminary review showed that there were very few studies where this had been done. Therefore we intend widening the scope to include non-comparative studies which report the percentage of patients in a telemedicine group who avoid travel. The subtle difference here is that we know that in any usual care group, a proportion of such patients could avoid travel. That is, in some patients who present at an outpatient clinic, for example, in the ordinary way, there will be some who will have been referred inappropriately, see Figure 1 . To reduce the risk of bias in the selected studies influencing our estimates of avoided travel, we will assess reliability of data, study performance and sample size. Scores from our assessments of these factors will be used to calculate a weighting factor.

\section{Literature search strategy}

Computerized literature searches will be performed using MEDLINE, HealthSTAR, EMBASE, CINAHL and the Cochrane Database of Systematic Reviews, with no date restrictions. The search strategy will make use of both controlled vocabulary, such as the National Library of Medicine's MeSH (Medical Subject Headings), and appropriate keywords.

Two approaches are possible. In the first, the search terms focus on the concepts of travel savings or avoided referrals through the use of telemedicine generally:

$$
\text { (phrase A) AND (phrase B) AND (phrase C) }
$$

where

phrase A = Telemedicine OR Telehealth OR telecare OR teleconsultation

phrase $\mathrm{B}=$ Avoid $^{*}$ OR prevent* OR decrease OR reduce OR unnecessar* OR sav* OR prevent phrase $\mathrm{C}=$ Travel OR referral OR visit OR admission OR hospitalization OR transfer* OR transport* OR cost saving* OR appointment OR cost stud* OR remote consultation* OR economic*

In the second, the search terms focus on telemedicine and its use in specific specialties:

(phrase A) AND (phrase D) 


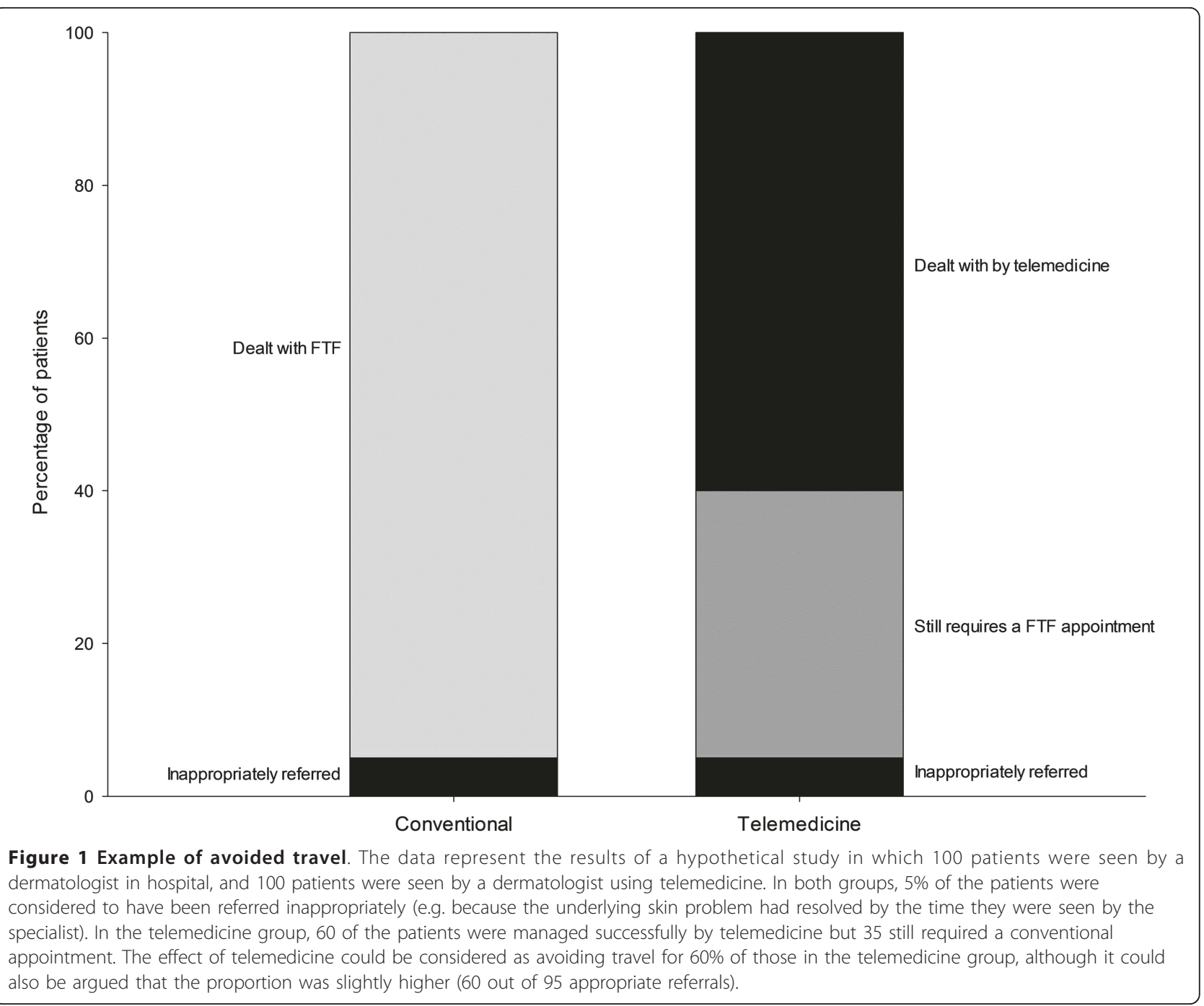

where

$$
\text { phrase D = Dermatology (for example) }
$$

In addition, telemedicine journals will be hand searched to identify any further relevant publications.

Grey literature (i.e. literature that is not commercially published) will be identified by searching the websites of health technology assessment and related agencies, and professional associations.

\section{Selection criteria}

The inclusion criteria will be:

(1) publications that consider travel or travel-related issues for patients, carers or health professionals, and include appropriate details on the data, methods of analysis and outcomes applicable to avoidance of travel. The proportion of avoided travel will be reported directly, or be easily calculable using the information in the paper;

(2) publications reporting studies in which at least 15 patients were managed using telemedicine;

(3) publications that contain an electronic abstract;

(4) publications in the English language.

The exclusion criteria will be:

(1) any paper not reporting the sample size or methodology for calculating the percentage of avoided travel; (2) articles where only anecdotal information on travel-related issues is given, without credible data and analysis;

(3) single case studies and series with fewer than 15 individuals;

(4) duplicate publications. 


\section{Article selection and data extraction}

At least two reviewers will independently apply the selection criteria to the titles and abstracts returned by the literature search. Full-text articles will be obtained for abstracts that meet the selection criteria and for undecided articles. Articles will be perused and included for review if they meet the selection criteria. Any discrepancies between reviewers' decisions will be resolved by consensus. At least two reviewers will independently extract data from the selected publications using a data abstraction form, created a priori. Any disagreements will be resolved by consensus.

Information extracted will include the medical specialty; setting and duration of study; patient numbers and characteristics; details of data related to avoidance of travel through use of telemedicine; telemedicine modality.

\section{Assessment of risk of bias}

Each study will be assigned to one of three classes related to the reliability of data:

(1) studies in which data on avoidance of travel or referrals through use of telemedicine were collected prospectively (score 3 );

(2) prospective studies in which estimates of travel or referrals avoided through use of telemedicine were based on the opinions of the investigators (score 2);

(3) retrospective or hypothetical studies (i.e. "thought" experiments), including appraisal of patient records (score 1).

These scores reflect differences in strength of evidence between prospective and retrospective studies, and between prospective collection of data and estimates based on expert opinion.

In assessing study performance, four areas will be considered:

(1) subjects: how recruited to the study;

(2) intervention: adequate description of the intervention used for the treatment of patients;

(3) data analysis: details of how the data were collected and analysed;

(4) outcomes: inclusion of individual subject data or a statistical summary, details of missing results, drop outs.

For each of these items, there will be an expectation of reasonable quality data and clear presentation of details. If all these areas are adequately covered, study performance can be regarded as good quality (score 3).
If there are limitations or omissions in one of the items, the study performance is fair (score 2). Limitations in more than one item would indicate poor performance quality (score 1).

The sample size will be taken as the number in the telemedicine intervention group. The sample size will be categorized as:

(1) large, i.e. $\geq 150$ (score 3 );

(2) medium, i.e. 50-149, (score 2);

(3) small, i.e. 15-49 (score 1).

For the purposes of our analysis each of the indices (study design, study performance and sample size) will be regarded as equally important. For each study, the scores for each index $(3,2$ or 1$)$ will be summed to give an individual study weighting factor with a minimum of 3 and a maximum of 9 (i.e. a 7-point scale).

At least two reviewers will determine scores for study design, study performance and sample size for each study. Any disagreements will be resolved by consensus.

\section{Data synthesis}

We expect that the number of publications dealing explicitly with travel savings through use of telemedicine will be small. We therefore propose a methodology that will take into account all the credible evidence, even some that is weak, rather than attempting to analyse effect size on a restricted dataset of the more rigorous studies.

The conventional approach to quantitative synthesis of the results from multiple studies is to conduct a metaanalysis. However, there are well known difficulties about attempting to combine results from studies which are too dissimilar [3]. Our hypothesis is that far too much heterogeneity exists between available studies to allow a meaningful meta-analysis of the data on avoided travel when telemedicine is used across all possible settings. There is also a dearth of randomized controlled trials in telemedicine. It follows that a different approach is required.

We propose instead to consider all credible evidence on avoided travel through telemedicine, and to fit a linear model which takes into account the relevant factors in the circumstances of the studies performed. We propose the use of stepwise multiple regression to identify which factors are significant. Possible factors are listed in Table 1 .

In accordance with the MOOSE recommendations for reporting the results of meta-analyses of observational studies, we will include graphical summaries of study estimates and any combined estimate, a table 
Table 1 Factors which may influence the avoided travel resulting from a particular telemedicine application

\begin{tabular}{|c|c|}
\hline \multirow[t]{3}{*}{ Modality } & Store and forward \\
\hline & Hybrid \\
\hline & Real time \\
\hline \multirow[t]{3}{*}{ Setting - referral source } & Home \\
\hline & Primary care \\
\hline & Hospital \\
\hline \multirow[t]{2}{*}{ Setting - referral location } & Metropolitan \\
\hline & Rural \\
\hline \multirow[t]{2}{*}{ Travel distance or travel time } & Long (> = 1 hour) \\
\hline & Short $(<1$ hour $)$ \\
\hline \multirow[t]{3}{*}{ Patient age } & Young (fetal and paediatric) \\
\hline & Adult \\
\hline & Elderly \\
\hline \multirow[t]{2}{*}{ Urgency } & Elective \\
\hline & Emergency \\
\hline \multirow[t]{2}{*}{ Purpose } & Diagnosis \\
\hline & Management (treatment, monitoring) \\
\hline \multirow[t]{2}{*}{ Health system } & Private \\
\hline & Public \\
\hline \multirow[t]{4}{*}{ Specialty } & Cardiology \\
\hline & Dermatology \\
\hline & Psychiatry \\
\hline & etc (see Table 4) \\
\hline
\end{tabular}

listing descriptive information for each study, results of sensitivity testing and any subgroup analysis, and an indication of the statistical uncertainty of findings [4].

The process of data synthesis is thus:

(1) study selection following the literature search;

(2) data extraction, including calculation of study weighting factors;

(3) regression analysis.

\section{Example}

The methodology above is illustrated by the example of teledermatology. A preliminary review of the literature (April 2010) found 20 studies in which the percentage of avoided travel through telemedicine could be inferred (see Table 2). The total number of patients in these studies was 5199. The mean percentage avoided travel in the 12 store-and-forward studies was $43 \%$. The mean proportion of patients who avoided travel in the 7 realtime studies and in a single study using a hybrid technique was $70 \%$, see Figure 2.

Dummy coding can be used to represent putative predictive variables as follows:

Modality - baseline (store and forward); hybrid; realtime

Country - baseline (North America); Europe; Rest of world

Patient group - baseline (all ages); only adults; only children

A linear model with all three putative predictors fits the data well $\left(R^{2}=0.761\right)$. However, the coefficients for country and for patient group are not significant. Simplifying the model to include only the significant predictor Modality produces $R^{2}=0.292$. It also shows that the coefficients for Hybrid and for Real-time are almost identical in size. If the single study in which a hybrid technique was used [5] is reclassified as real-time, then the model $\left(R^{2}=0.291\right)$ is:

$$
\mathrm{A}=42.8+24.5 . \mathrm{M}
$$

where A is percentage of avoided travel;

$M=0$ if store-and-forward is used and $M=1$ if real-time telemedicine is used.

That is, use of store and forward teledermatology was associated with avoided travel for a mean of $43 \%$ of the patients in the studies $(P<0.001)$. The improvement in the proportion of patients who avoided travel $(25 \%)$ when real-time telemedicine was employed is significant $(P=0.014)$, Table 3 .

\section{Discussion}

Our proposed review is intended as an appraisal of the travel savings achievable through telemedicine. Our methodology takes a relatively simple approach to the assessment of studies, and makes a number of assumptions. For example, the decision to allocate equal weights to reliability of data, study performance and sample size is arbitrary. An earlier approach to quality assessment of telemedicine studies used differential weights, with the weight for study performance being twice that for study design [6]. It would also be possible to classify both reliability of data and study performance 


\begin{tabular}{|c|c|c|c|c|c|c|c|c|c|c|c|}
\hline Author & Year & $\begin{array}{l}\text { Percentage of } \\
\text { patients who } \\
\text { avoided travel }\end{array}$ & $\begin{array}{c}\text { Study } \\
\text { design (a) }\end{array}$ & $\begin{array}{l}\text { Sample } \\
\text { size }\end{array}$ & Weight (b) & Country & Modality (c) & Urgency & Referral setting & Patient age & Comment \\
\hline $\begin{array}{l}\text { Whited J } \\
\text { [10] }\end{array}$ & 2002 & 18.5 & 3 & 135 & 8 & USA & $S / F$ & Elective & Primary care & Mean 61 years (SD 13.8) & \\
\hline $\begin{array}{c}\text { Bowns I } \\
\text { [11] }\end{array}$ & 2006 & 42.4 & 3 & 92 & 8 & UK & $S / F$ & Elective & Primary care & 16 years and over & Excludes children \\
\hline $\begin{array}{c}\text { White H } \\
\text { [12] }\end{array}$ & 1999 & 25.0 & 2 & 40 & 4 & UK & $S / F$ & Elective & Primary care & Not stated & \\
\hline $\begin{array}{l}\text { Loane M } \\
\text { [13] }\end{array}$ & 2000 & 31.3 & 3 & 96 & 8 & UK & $S / F$ & Elective & Primary care & 7 months to 81 years & $\begin{array}{l}\text { Loane } 2000 \text { is two arms of the } \\
\text { same study }\end{array}$ \\
\hline $\begin{array}{l}\text { Taylor P } \\
\text { [14] }\end{array}$ & 2001 & 31.4 & 2 & 376 & 8 & UK & $S / F$ & Elective & $\begin{array}{l}\text { Hospital OPD } \\
\quad \text { clinic }\end{array}$ & Not stated & $\begin{array}{l}376 \text { tele-assessments; } 194 \\
\text { patients }\end{array}$ \\
\hline Knol A [15] & 2006 & 51.4 & 2 & 306 & 8 & Netherlands & $S / F$ & Elective & Primary care & $\begin{array}{c}0-96 \text { years (in larger sample of } \\
505 \text { patients) }\end{array}$ & \\
\hline $\begin{array}{l}\text { Wootton R } \\
\text { [16] }\end{array}$ & 2000 & 53.9 & 3 & 102 & 8 & UK & $R / T$ & Elective & Primary care & $\begin{array}{c}4 \text { months to } 89 \text { years (in larger } \\
\text { sample of } 204 \text { patients) }\end{array}$ & \\
\hline $\begin{array}{l}\text { Loane M } \\
\text { [13] }\end{array}$ & 2000 & 55.2 & 3 & 96 & 8 & UK & $R / T$ & Elective & Primary care & 7 months to 81 years & $\begin{array}{l}\text { Loane } 2000 \text { is two arms of the } \\
\text { same study }\end{array}$ \\
\hline $\begin{array}{l}\text { Lamminen } \\
\quad H[17]\end{array}$ & 2000 & 72.0 & 2 & 25 & 7 & Finland & $R / T$ & Elective & Primary care & Mean 45 years (range 4-92) & \\
\hline $\begin{array}{l}\text { Granlund } \\
\mathrm{H}[18]\end{array}$ & 2003 & 81.3 & 1 & 16 & 4 & Finland & $R / T$ & Elective & Primary care & $\begin{array}{c}\text { Mean } 40 \text { years (SD 21), both } \\
\text { groups }\end{array}$ & $\begin{array}{l}70 \% \text { of } 23 \text { patients in video } \\
\text { group said they had not visited } \\
\text { hospital at } 6 \text {-month follow-up }\end{array}$ \\
\hline $\begin{array}{l}\text { Chen T } \\
\text { [19] }\end{array}$ & 2010 & 94.0 & 1 & 429 & 6 & USA & $S / F$ & Elective & Primary care & $\begin{array}{c}\text { Mean } 5.9 \text { years (range } 0-12 \\
\text { years } 11 \text { months) }\end{array}$ & $\begin{array}{l}\text { Only children ( } 12 \text { years or } \\
\text { younger) }\end{array}$ \\
\hline $\begin{array}{c}\text { Romero } G \\
{[5]}\end{array}$ & 2009 & 70.0 & 3 & 368 & 9 & Spain & Hybrid & Elective & Primary care & $\begin{array}{c}\text { Mean } 36 \text { years (range } 2 \\
\text { months }-86 \text { years) [but this } \\
\text { includes an extra control } \\
\text { group] }\end{array}$ & $\begin{array}{l}192 \text { pts had S/F alone; } 176 \text { had } \\
\text { S/F and then Real-time }\end{array}$ \\
\hline $\begin{array}{l}\text { Eminovic N } \\
\qquad[20]\end{array}$ & 2009 & 39.0 & 3 & 200 & 9 & Netherlands & $S / F$ & Elective & Primary care & Mean approx 43 years & \\
\hline $\begin{array}{l}\text { Moreno- } \\
\text { Ramirez D } \\
{[21]}\end{array}$ & 2007 & 51.2 & 2 & 2009 & 8 & Spain & $S / F$ & ?Urgent & Primary care & Mean 41.5 years & $\begin{array}{l}\text { Pigmented skin lesions - } \\
\text { possible skin cancer }\end{array}$ \\
\hline Klaz | [22] & 2005 & 77.9 & 2 & 435 & 7 & Israel & $S / F$ & Elective & Primary care & Mean 22.4 years (range 18-39) & Excludes children \\
\hline $\begin{array}{l}\text { Eminovic N } \\
\qquad[23]\end{array}$ & 2003 & 22.9 & 2 & 96 & 7 & Netherlands & $\mathrm{S} / \mathrm{F}$ & Elective & Primary care & Mean 35 years & Patients provided the images \\
\hline $\begin{array}{l}\text { Oakley A } \\
{[24]}\end{array}$ & 2000 & 88.0 & 2 & 109 & 6 & $\begin{array}{l}\text { New } \\
\text { Zealand }\end{array}$ & $R / T$ & Elective & Primary care & $\begin{array}{l}\text { Mean } 41 \text { years (range } 1 \text { month } \\
\text { to } 94 \text { years) [may include non- } \\
\text { telederm patients as well) }\end{array}$ & \\
\hline $\begin{array}{c}\text { Burgiss S } \\
{[25]}\end{array}$ & 1997 & 92.0 & 1 & 87 & 4 & USA & $R / T$ & Elective & Primary care & Not stated & \\
\hline $\begin{array}{l}\text { Gilmour E } \\
{[26]}\end{array}$ & 1998 & 50.8 & 3 & 61 & 8 & UK & $R / T$ & Elective & Primary care & $\begin{array}{c}3 \text { months to } 83 \text { years (for all } \\
126 \text { patients) }\end{array}$ & \\
\hline $\begin{array}{l}\text { Jemec } G \\
{[27]}\end{array}$ & 2008 & 27.3 & 1 & 121 & 4 & $\begin{array}{l}\text { Denmark } \\
\text { (Faroes) }\end{array}$ & $S / F$ & Elective & Primary care & Mean 37 years (SD 20) & \\
\hline
\end{tabular}




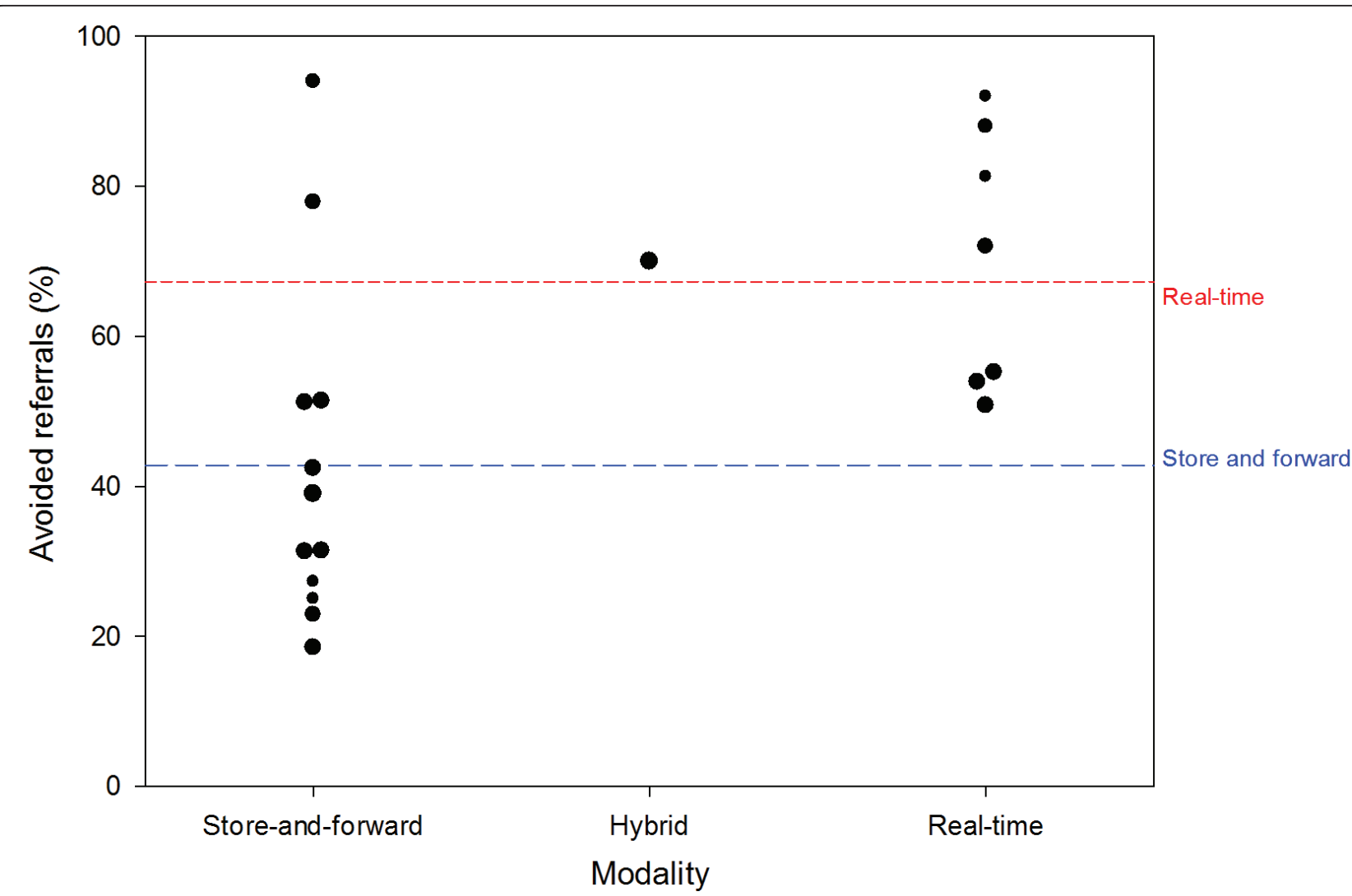

Figure 2 Avoided referrals from primary care. Avoided referrals as a result of the use of teledermatology in referrals from primary care (20 studies from 1997-2010). The areas of the symbols are proportional to the study weights. The broken lines represent the avoided travel expected from the fitted model (see text).

in more detail $[6,7]$. These are matters that might be considered in future studies.

The use of stepwise regression to identify significant factors has been used previously in meta-regression $[8,9]$. Because of the relatively small dataset in the dermatology example $(n=20)$, it was not possible to explore the significance of all possible factors. However, the model appeared to produce sensible results when three factors were investigated. With a large dataset, such as that likely to result from the proposed systematic review, it would be possible to explore most or all of the possible factors in Table 1 and to do so using a robust exploration technique, such as resampling.

Some matters may need to be developed further after the review commences. One of these is how the studies will be classified in terms of the medical specialties involved, since there does not appear to be an internationally-accepted system for classification. Our proposal, a pragmatic scheme, is shown in Table 4. The significance of other factors, such as study setting and urgency of consultations is unclear at this stage and will need to be explored after more data become available.

Numbers of studies in some specialties may be small and will therefore provide estimates of travel savings which have a high level of uncertainty. Nevertheless, such results are expected to provide helpful initial indications and should assist in defining areas for future work.

The example analysis of dermatology studies suggests that substantial avoided patient travel can be expected through the use of store-and-forward telemedicine. The results also provide an estimate of the additional value of real-time telemedicine, a technique which is generally speaking less convenient and more expensive than store-and-forward telemedicine. Service planners can use this information to weigh up the costs and benefits of the two approaches. A systematic review across the whole of telemedicine with data synthesis in accordance with the proposals in the present paper therefore appears likely to provide important information for those planning the future introduction of telemedicine services around the world. 
Table 3 Coefficients of fitted model (using Modality as a predictor)

\begin{tabular}{lccccc}
\hline & \multicolumn{2}{c}{ Unstandardized coefficients } & Standardized coefficient & & \\
& B & SE & Beta & t & P-value \\
\hline (Baseline) & 42.816 & 5.616 & & 7.6 & $<0.001$ \\
Dummy_modality2 & 24.487 & 9.011 & 0.539 & 2.7 & 0.014 \\
\hline
\end{tabular}

Table 4 Categories of specialties

\begin{tabular}{|c|c|c|c|}
\hline Specialty & Subspecialty & ... Specialty & ... Subspecialty \\
\hline \multirow[t]{7}{*}{ Allied Health } & & Pathology & \\
\hline & Chiropractice & & Anatomical \\
\hline & Occupational therapy & & Bacteriology \\
\hline & Physiotherapy & & Breast cancer \\
\hline & Podiatry & & Clinical chemistry \\
\hline & Rehabilitation & & Cytopathology \\
\hline & Speech therapy & & Dermatology \\
\hline \multirow[t]{4}{*}{ Anaesthesia } & & & Forensic \\
\hline & Intensive care & & Haematology \\
\hline & Obstetric & & Histology \\
\hline & Pain & & Immunology \\
\hline \multirow[t]{2}{*}{ Emergency medicine } & & & Microbiology \\
\hline & & & Neuropathology \\
\hline \multirow[t]{2}{*}{ General practice } & & Public Health & \\
\hline & & & Environmental \\
\hline \multirow[t]{25}{*}{ Internal Medicine } & & & Occupational \\
\hline & Cardiology & & Preventive \\
\hline & Dermatology & Radiology & \\
\hline & Endocrinology & & Diagnostic \\
\hline & Gastroenterology & & Neuroradiology \\
\hline & Genetics & & Nuclear medicine \\
\hline & Geriatrics & & Oncology \\
\hline & Haematology & & Radiography \\
\hline & Hepatology & & Radiotherapy \\
\hline & Immunology & & Ultrasound \\
\hline & Infectious diseases & Surgery & \\
\hline & Intensive care & & Abdominal \\
\hline & Maternal/fetal & & Burns \\
\hline & Neurology & & Colon/Rectal \\
\hline & Oncology & & ENT \\
\hline & Ophthalmology & & Hand \\
\hline & Preventive & & Head and neck \\
\hline & Renal & & Maxillo-Facial \\
\hline & Reproductive & & Neurosurgery \\
\hline & Respiratory & & Oncology \\
\hline & Rheumatology & & Ophthalmology \\
\hline & Sexual and reproductive health & & Orthopaedics \\
\hline & Thoracic & & Plastic \\
\hline & Tropical diseases & & Spinal \\
\hline & Tropical medicine & & Thoracic \\
\hline \multirow[t]{2}{*}{ Mental Health } & & & Urology \\
\hline & Psychiatry & & Vascular \\
\hline
\end{tabular}


Table 4 Categories of specialties (Continued)

\begin{tabular}{|c|c|}
\hline & Psychology \\
\hline \multicolumn{2}{|l|}{ Nursing } \\
\hline & Diabetes and pregnancy \\
\hline & Midwife \\
\hline & Paediatrics \\
\hline \multicolumn{2}{|c|}{ Obstetrics and gynaecology } \\
\hline & Colposcopy \\
\hline & Oncology \\
\hline & Reproductive \\
\hline & Urogynaecology \\
\hline \multicolumn{2}{|l|}{ Other } \\
\hline & Dietetics \\
\hline & Hospital pharmacy \\
\hline & Proxy consultant \\
\hline & Wound care \\
\hline \multirow[t]{22}{*}{ Paediatri } & \\
\hline & Cardiology \\
\hline & Dentistry \\
\hline & Dermatology \\
\hline & Endocrinology \\
\hline & Gastroenterology \\
\hline & Genetics \\
\hline & Haematology \\
\hline & Immunology \\
\hline & Infectious diseases \\
\hline & Intensive care \\
\hline & Metabolic diseases \\
\hline & Neonatal \\
\hline & Neurology \\
\hline & Oncology \\
\hline & Physiotherapy \\
\hline & Psychiatry \\
\hline & Radiology \\
\hline & Renal \\
\hline & Respiratory \\
\hline & Rheumatology \\
\hline & Surgery \\
\hline
\end{tabular}

\section{Acknowledgements}

The work was supported by the Norwegian regional health authority, Helse Nord (RW), by the Iranian government (KB) and by the University of Wollongong $(\mathrm{DH})$

\section{Author details}

${ }^{1}$ Norwegian Centre for Integrated Care and Telemedicine, University Hospital of North Norway, PO Box 6060, N-9038 Tromsø, Norway. ${ }^{2}$ Australian e-Health Research Centre, CSIRO, Leeuwin Centre, 65 Brockway Road, Floreat, WA 6014, Australia. ${ }^{3}$ School of Information Systems and Technology, University of Wollongong, Wollongong, NSW 2522, Australia. ${ }^{4}$ Research Centre for Modelling in Health, Kerman University of Medical Sciences, Kerman, Iran.

\section{Authors' contributions}

KB was responsible for the research question. RW formulated and developed the methodological concept. All authors contributed to reviewing data and writing the manuscript. All authors read and approved the final manuscript.

\section{Competing interests}

The authors declare that they have no competing interests.

Received: 19 April 2010 Accepted: 8 August 2011

Published: 8 August 2011

\section{References}

1. Wootton R, Tait A, Croft A: Environmental aspects of health care in the Grampian NHS region and the place of telehealth. J Telemed Telecare 2010, 16:215-20.

2. Morton SC, Adams JL, Suttorp MJ, Shekelle PG: Meta-regression Approaches: What, Why, When, and How? Technical Review 8 [http://www.ncbi.nlm.nih. gov/bookshelf/br.fcgi?book=hstechrev\&part=A19327], (Prepared by Southern California-RAND Evidence-based Practice Center, under Contract No 290-97-0001). AHRQ Publication No. 04-0033. Rockville, MD: Agency for Healthcare Research and Quality. March 2004. 
3. Sharpe D: Of apples and oranges, file drawers and garbage: why validity issues in meta-analysis will not go away. Clin Psychol Rev 1997, 17:881-901.

4. Stroup DF, Berlin JA, Morton SC, Olkin I, Williamson GD, Rennie D, Moher D, Becker BJ, Sipe TA, Thacker SB: Meta-analysis of observational studies in epidemiology: a proposal for reporting. Meta-analysis Of Observational Studies in Epidemiology (MOOSE) group. JAMA 2000, 283:2008-12.

5. Romero G, Sánchez P, García M, Cortina P, Vera E, Garrido JA: Randomized controlled trial comparing store-and-forward teledermatology alone and in combination with web-camera videoconferencing. Clin Exp Dermatol 2010, 35:311-7.

6. Hailey D, Ohinmaa A, Roine R: Study quality and evidence of benefit in recent assessments of telemedicine. J Telemed Telecare 2004, 10:318-324.

7. Jovell AJ, Navarro-Rubio MD: Evaluation of scientific evidence. Med Clin (Barc) 1995, 105:740-743.

8. Maziekas MT, LeMura LM, Stoddard NM, Kaercher S, Martucci T: Follow up exercise studies in paediatric obesity: implications for long term effectiveness. Br J Sports Med 2003, 37:425-9.

9. Amin AP, Mamtani MR, Kulkarni H: Factors influencing the benefit of adjunctive devices during percutaneous coronary intervention in STsegment elevation myocardial infarction: meta-analysis and metaregression. J Interv Cardiol 2009, 22:49-60.

10. Whited JD, Hall RP, Foy ME, Marbrey LE, Grambow SC, Dudley TK, Datta S, Simel DL, Oddone EZ: Teledermatology's impact on time to intervention among referrals to a dermatology consult service. Telemed J E Health 2002, 8:313-21.

11. Bowns IR, Collins K, Walters SJ, McDonagh AJ: Telemedicine in dermatology: a randomised controlled trial. Health Technol Assess 2006, 10(43):iii-iv-ix-xi, 1-39.

12. White H, Gould D, Mills W, Brendish L: The Cornwall dermatology electronic referral and image-transfer project. J Telemed Telecare 1999, 5(Suppl 1):85-6.

13. Loane MA, Bloomer SE, Corbett R, Eedy DJ, Hicks N, Lotery HE, Mathews C, Paisley J, Steele K, Wootton R: A comparison of real-time and store-andforward teledermatology: a cost-benefit study. Br J Dermatol 2000, 143:1241-7.

14. Taylor P, Goldsmith P, Murray K, Harris D, Barkley A: Evaluating a telemedicine system to assist in the management of dermatology referrals. Br J Dermatol 2001, 144:328-33.

15. Knol A, van den Akker TW, Damstra RJ, de Haan J: Teledermatology reduces the number of patient referrals to a dermatologist. J Telemed Telecare 2006, 12:75-8.

16. Wootton R, Bloomer SE, Corbett R, Eedy DJ, Hicks N, Lotery HE, Mathews C, Paisley J, Steele K, Loane MA: Multicentre randomised control trial comparing real time teledermatology with conventional outpatient dermatological care: societal cost-benefit analysis. BMJ 2000, 320:1252-6.

17. Lamminen $\mathrm{H}$, Tuomi ML, Lamminen J, Uusitalo $\mathrm{H}$ : A feasibility study of realtime teledermatology in Finland. J Telemed Telecare 2000, 6:102-7.

18. Granlund H, Thoden CJ, Carlson C, Harno K: Realtime teleconsultations versus face-to-face consultations in dermatology: immediate and sixmonth outcome. J Telemed Telecare 2003, 9:204-9.

19. Chen TS, Goldyne ME, Mathes EF, Frieden IJ, Gilliam AE: Pediatric teledermatology: observations based on 429 consults. J Am Acad Dermatol 2010, 62:61-6.

20. Eminović N, de Keizer NF, Wyatt JC, ter Riet G, Peek N, van Weert HC, Bruijnzeel-Koomen CA, Bindels PJ: Teledermatologic consultation and reduction in referrals to dermatologists: a cluster randomized controlled trial. Arch Dermatol 2009, 145:558-64.

21. Moreno-Ramirez D, Ferrandiz L, Nieto-Garcia A, Carrasco R, MorenoAlvarez P, Galdeano R, Bidegain E, Rios-Martin JJ, Camacho FM: Store-andforward teledermatology in skin cancer triage: experience and evaluation of 2009 teleconsultations. Arch Dermatol 2007, 143:479-84, Erratum in: Arch Dermatol 2007,143:886

22. Klaz I, Wohl Y, Nathansohn N, Yerushalmi N, Sharvit S, Kochba I, Brenner S: Teledermatology: quality assessment by user satisfaction and clinical efficiency. Isr Med Assoc J 2005, 7:487-90.

23. Eminović N, Witkamp L, Ravelli AC, Bos JD, van den Akker TW, Bousema MT, Henquet CJ, Koopman RJ, Zeegelaar JE, Wyatt JC: Potential effect of patient-assisted teledermatology on outpatient referral rates. $J$ Telemed Telecare 2003, 9:321-7.
24. Oakley AM, Kerr P, Duffill M, Rademaker M, Fleischl P, Bradford N, Mills C: Patient cost-benefits of realtime teledermatology-a comparison of data from Northern Ireland and New Zealand. J Telemed Telecare 2000, 6:97-101.

25. Burgiss SG, Julius CE, Watson HW, Haynes BK, Buonocore E, Smith GT: Telemedicine for dermatology care in rural patients. Telemed J 1997, 3:227-33.

26. Gilmour E, Campbell SM, Loane MA, Esmail A, Griffiths CE, Roland MO, Parry EJ, Corbett RO, Eedy D, Gore HE, Mathews C, Steel K, Wootton R: Comparison of teleconsultations and face-to-face consultations: preliminary results of a United Kingdom multicentre teledermatology study. Br J Dermatol 1998, 139:81-7.

27. Jemec GB, Heidenheim M, Dam TN, Vang E: Teledermatology on the Faroe Islands. Int J Dermatol 2008, 47:891-3.

\section{Pre-publication history}

The pre-publication history for this paper can be accessed here: http://www.biomedcentral.com/1472-6963/11/185/prepub

doi:10.1186/1472-6963-11-185

Cite this article as: Wootton et al: Estimating travel reduction associated with the use of telemedicine by patients and healthcare professionals: proposal for quantitative synthesis in a systematic review. BMC Health Services Research 2011 11:185.

\section{Submit your next manuscript to BioMed Central and take full advantage of:}

- Convenient online submission

- Thorough peer review

- No space constraints or color figure charges

- Immediate publication on acceptance

- Inclusion in PubMed, CAS, Scopus and Google Scholar

- Research which is freely available for redistribution

Submit your manuscript at www.biomedcentral.com/submit
Ciomed Central 